\title{
Building a Company Step by Step, Ch. 2: The Path to the Epiphany
}

Jon Eckhardt (University of Wisconsin-Madison)

KEYWORDS: Startups, customer discovery.

EIX is featuring interviews that explore the principles outlined in Steve Blank and Bob Dorf's book, "The Startup Owners Manual: The Step-by-Step Guide for Building a Great Company." This interview with Max Fergus, founder of Live Undiscovered Music Inc. (LÜM), focuses on Chapter 2, The Path to the Epiphany: The Customer Development Model.

Fergus, who is a University of Wisconsin graduate, started LÜM as a music sharing platform for emerging musicians who want to connect more deeply with fans, and for music lovers who want a more personal connection with musicians they admire. Unlike streaming services, which pay a fraction of a cent to the musician for each listen, LÜM allows listeners to support the musician directly through a virtual gifting system, with virtual money that the musician can turn into cash. And for listeners, LÜM allows a more authentic and personalized experience and introduces them to talented performers beyond the mainstream. In this interview, Fergus talks about what inspired him to launch his company, which early in 2021 had attracted more than 100,000 musicians.

\section{Listen}

This video is also available as a podcast.

Link to video

EIX

(https://soundcloud.com/user-876519212-189256831).

Ch 2 Max $\quad$ Fergus V2

(https://soundcloud.com/user-876519212-189256831/c

h-2-max-fergus-v2) 